\title{
ERRATUM
}

\section{Recognising and supporting self in dementia: a new way to facilitate a person-centred approach to dementia care - ERRATUM}

\section{FIONA KELLY}

doi:Io.roi7/Sor44686Xogoo8708, Published by Cambridge University Press, I4 August 2009.

Most unfortunately there was an error in the penultimate sentence of this paper. We sincerely apologise to Dr Fiona Kelly of the University of Stirling for the error. The correct version should read:

This paper has developed a deeper understanding of the relationships between a carer's understanding of the selfhood of their patients, its translation into the recognition and support (or not) of the person in care interactions, and the transactional repercussions for the wellbeing of the person. In so doing, it has offered a new way to facilitate a person-centred approach to dementia care.

\section{Reference}

Kelly, F. 20I0. Recognising and supporting self in dementia: a new way to facilitate a person-centred approach to dementia care. Ageing \& Society, 30, I, IO3-I24. 